Article

\title{
Organic Light-Emitting Diodes Based on Phthalimide Derivatives: Improvement of the Electroluminescence Properties
}

\author{
Frédéric Dumur ${ }^{1, *\left(\mathbb{D}, \text { Malika Ibrahim-Ouali }^{2} \text { and Didier Gigmes }\right.}{ }^{1}$ \\ 1 Aix Marseille Univ, CNRS, Institut de Chimie Radicalaire ICR, UMR 7273, F-13397 Marseille, France; \\ didier.gigmes@univ-amu.fr \\ 2 Aix Marseille Univ, CNRS, Centrale Marseille, iSm2, F-13397 Marseille, France; malika.ibrahim@univ-amu.fr \\ * Correspondence: frederic.dumur@univ-amu.fr; Tel.: +33-(0)4-91-28-27-48
}

Received: 4 March 2018; Accepted: 29 March 2018; Published: 31 March 2018

\begin{abstract}
In this study, a phthalimide-based fluorescent material has been examined as a green emitter for multilayered organic light-emitting diodes (OLEDs). By optimizing the device stacking, a maximum brightness of $28,450 \mathrm{~cd} / \mathrm{m}^{2}$ at $11.0 \mathrm{~V}$ and a maximum external quantum efficiency of $3.11 \%$ could be obtained. Interestingly, OLEDs fabricated with Fluo-2 presented a 20-fold current efficiency improvement compared to the previous results reported in the literature, evidencing the crucial role of the device stacking in the electroluminescence (EL) performance of a selected emitter. Device lifetime was also examined and an operational stability comparable to that reported for a standard triplet emitter i.e., bis(4-methyl-2,5-diphenyl-pyridine)iridium(III) acetylacetonate [(mdppy) ${ }_{2}$ Iracac] was evidenced.
\end{abstract}

Keywords: OLED; fluorescence; phosphorescence; green; device architecture

\section{Introduction}

Since the discovery of the green electroluminescence of tris(8-hydroxyquinoline)aluminum $\mathrm{Alq}_{3}$ by Tang and van Slyke in 1987 [1], a revolution in the field of electroluminescence on basis of organic materials has been initiated. This research field has garnered significant interest and seen a constant growth, offering the opportunity to the organic light-emitting diode (OLED) technology to immensely progress in terms of materials, device architecture and operational lifetime [2-4]. Typically, an OLED consists in a stack of organic layers sandwiched between two electrodes. For light emission, one of the electrodes is transparent and in most of the case, the transparent electrode is the anode made of a thin layer of conductive oxide, namely an indium tin oxide (ITO). Despite the outstanding improvements achieved in terms of molecular design and photoluminescence quantum yields, electroluminescence (EL) performance for a given emitter is nonetheless dependent of its PL characteristics but also of the device architecture used to fabricate OLEDs. Thus, a performant emitter investigated in a none-adapted structure will furnish only low electron-to-photon efficiencies. Face to this consideration, promising light-emitting materials such as Firpic [5], $\operatorname{Ir}(\text { ppy })_{3}$ [6], $\operatorname{Ir}(\text { piq })_{3}$ [7], DCJTB [8], MEH-PPV [9-11] or DPVBi [12] have been extensively studied in the literature so that some of these materials have been largely popularized by the number of publications devoted to their studies. Among emitters, phthalimide-based materials are an attractive class of materials by their good electron-transport abilities $[13,14]$ and their remarkable electron-accepting ability $[15,16]$. When combined with the oligophenylenevinylene core, materials with a wide bandgap can be designed, the phthalimide part conferring the electron-transport properties lacking to the oligophenylene central core [17]. To date, this family of fluorescent materials has only been scarcely investigated in the literature. In 2006, $5^{\prime}-\left(\left(1 E, 1^{\prime} E\right)-(2,5-b i s(\right.$ octyloxy)-1,4-phenylene)bis(ethene-2,1-diyl))bis(2-cyclohexylisoindoline-1,3-dione) 
Fluo-1 was incorporated as the emitter for single-layered devices [ITO/PEDOT:PSS (50 nm)/emitting layer $/ \mathrm{LiF}(1 \mathrm{~nm}) / \mathrm{Al}]$, furnishing a maximum brightness of $6200 \mathrm{~cd} / \mathrm{m}^{2}$ at $12 \mathrm{~V}$, a turn-on voltage of $6.0 \mathrm{~V}$ and a maximum current and power efficiency of $1.78 \mathrm{~cd} / \mathrm{A}$ and $0.46 \mathrm{~lm} / \mathrm{W}$ respectively. More recently, in 2009, its analogue 5'-((1E,1'E)-(2,5-bis(dodecyloxy)-1,4-phenylene)bis(ethene-2,1diyl))bis(2-cyclohexyl-isoindoline-1,3-dione) Fluo-2 differing from Fluo-1 by the length of the alkyl chains was examined as a dopant for PVK (poly(N-vinylcarbazole) See Figure 1) [18].

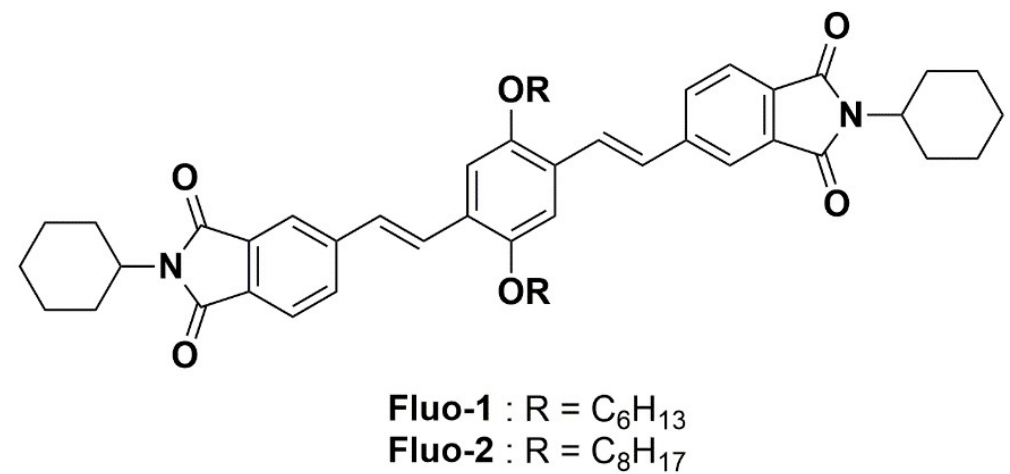

Figure 1. Chemical structures of Fluo-1 and Fluo-2.

The resulting solution-processed devices [ITO/PEDOT:PSS/emitting layer/Ca(50 nm)/Al(100 nm)] only furnished low EL characteristics, with a turn-on voltage of $7.2 \mathrm{~V}$, a maximum luminance of $1358 \mathrm{~cd} / \mathrm{m}^{2}$ and a maximum current efficiency of $0.57 \mathrm{~cd} / \mathrm{A}$. In this work, we propose to examine anew the EL performance of Fluo-2. Precisely, this fluorescent material was studied in the restrictive context of single-layered organic light-emitting diodes and only low EL characteristics were determined in these conditions. In this work, Fluo-2 is revisited in the context of multilayered vacuum-processed devices with three different device structures aiming at optimizing its EL characteristics. By using an appropriate device stacking, an enhanced brightness as well as a higher electron-to-photon conversion could be obtained.

\section{Materials and Methods}

All materials used for the device fabrication were purchased from Lumtec with the best purity available and used as received. 5,5'-((1E,1'E)-(2,5-bis(dodecyloxy)-1,4-phenylene)bis(ethene-2,1diyl))bis(2-cyclohexylisoindoline-1,3-dione) Fluo-2 was synthesized as previously reported [18]. OLEDs were fabricated onto cleaned indium tin oxide (ITO) glass substrates with sheet resistance of $10-12 \Omega /$ sq. Prior to organic layer deposition, the ITO substrates were successively washed with acetone, ethanol and isopropanol in an ultrasonic bath for $10 \mathrm{~min}$ before surface treatment with UV-ozone plasma for $20 \mathrm{~min}$. a first layer of $\mathrm{MoO}_{3}(5 \mathrm{~nm})$ was deposited on top of ITO to act as a hole injecting material. Organic layers [fluorescent emitter Fluo-2, 2,9-dimethyl-4,7diphenyl-1,10-phenanthroline (BCP), tris(8-quinolinolato)-aluminum(III) (Alq $_{3}$ ) or 1,3,5-tris(N-phenylbenzimidizol-2-yl)benzene (TPBi)] were then sequentially deposited at a rate of $2-4 \AA / \mathrm{s}$ under secondary vacuum. Finally, a 1-nm-thick LiF layer and an 80-nm-thick aluminum cathode layer were successively deposited on the substrates in high vacuum environment through a shadow mask by thermal evaporation. The resulting device had the following structure: $\mathrm{ITO} / \mathrm{MoO}_{3}(5 \mathrm{~nm}) /$ Fluo-2 $(40 \mathrm{~nm}) / \mathrm{TPBi}(30 \mathrm{~nm}) / \mathrm{LiF}(1 \mathrm{~nm}) / \mathrm{Al}(80 \mathrm{~nm})$ (device configuration A) or ITO/ $\mathrm{MoO}_{3}(5 \mathrm{~nm}) /$ Fluo-2 $(40 \mathrm{~nm}) / \mathrm{BCP}(10 \mathrm{~nm}) / \mathrm{Alq}_{3}(20 \mathrm{~nm}) / \mathrm{LiF}(1 \mathrm{~nm}) / \mathrm{Al}(80 \mathrm{~nm})$ (device configuration B). Device configuration $\mathrm{C}$ differs from the device configuration $\mathrm{A}$ by the introduction of a $\mathrm{BCP}$ interlayer of $10 \mathrm{~nm}$ between the emissive layer and TPBi. The EL spectra, Commission Internationale de l'Eclairage (CIE) coordinates, current-voltage and brightness-voltage characteristics of the devices were recorded with an External Quantum Efficiency Measurement System (model C9920-12) of Hamamatsu Photonics K.K. The device architectures and the chemical structures of the materials that were used in this work are presented in the Figure 2. 

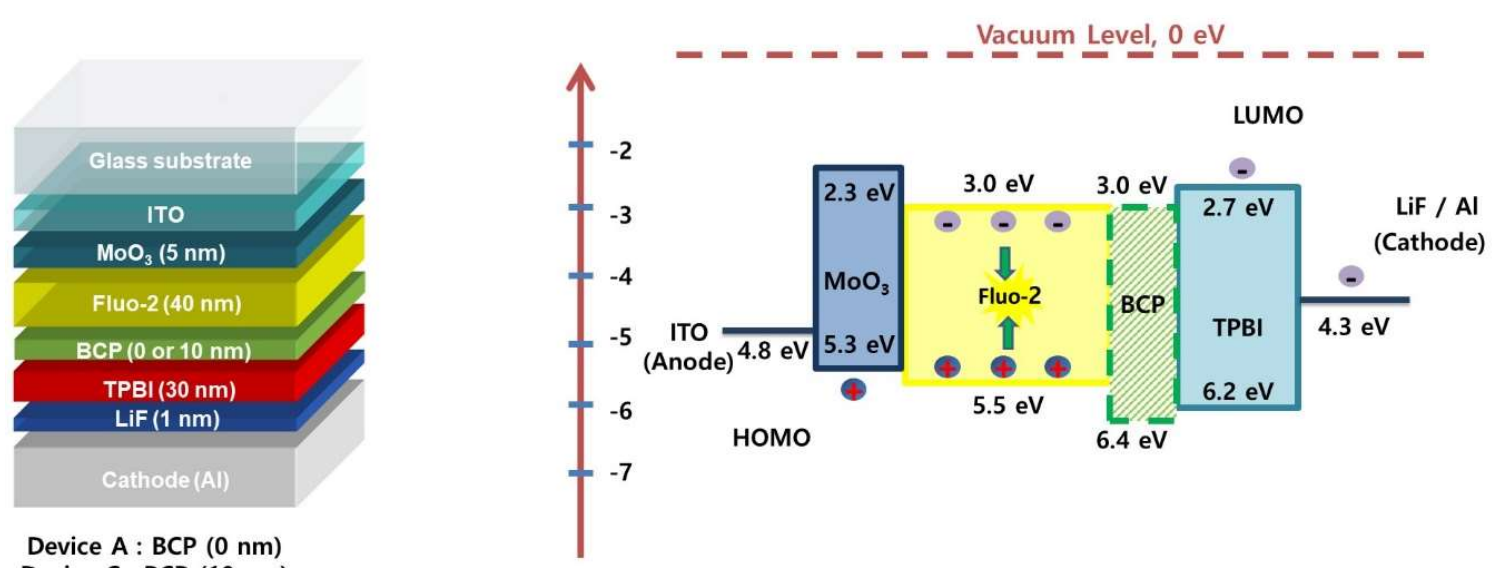

Device A : BCP $(0 \mathrm{~nm})$
Device C : BCP $(10 \mathrm{~nm})$
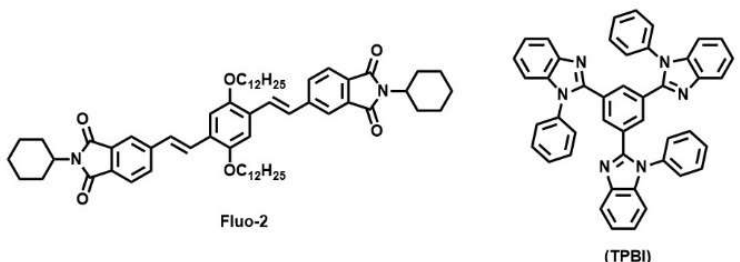

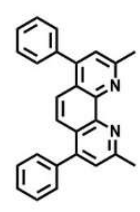

(BCP)

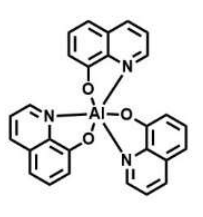

$\left(\mathrm{A} \mid q_{3}\right)$

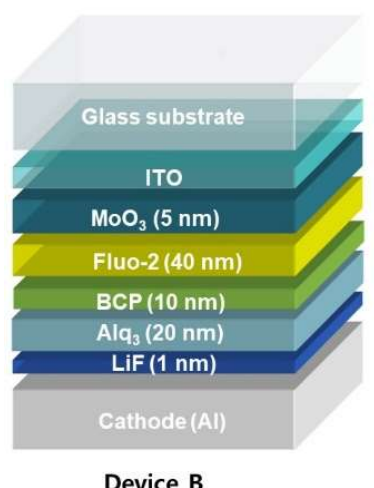

Vacuum Level, $0 \mathrm{eV}$
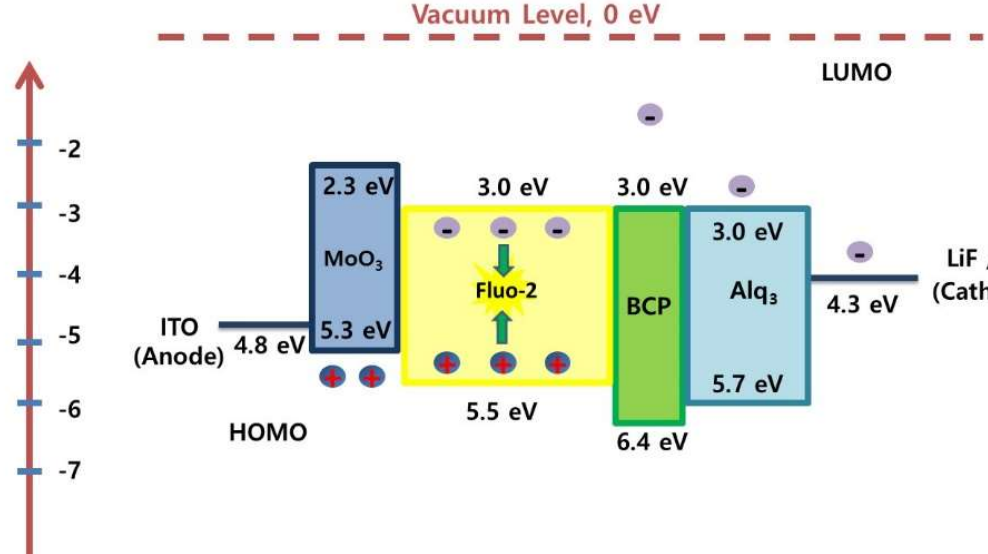

-

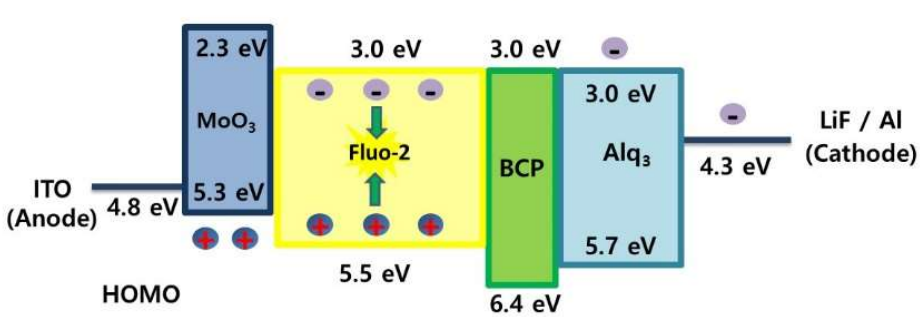

Figure 2. Device configurations and formulas of the different materials used to fabricate organic lightemitting diodes (OLEDs).

\section{Results and Discussion}

To examine the EL performance of Fluo-2, two standard device configurations were investigated, namely ITO/ $\mathrm{MoO}_{3}(5 \mathrm{~nm}) /$ Fluo-2 $(40 \mathrm{~nm}) / \mathrm{TPBi}(30 \mathrm{~nm}) / \mathrm{LiF}(1 \mathrm{~nm}) / \mathrm{Al}(80 \mathrm{~nm})$ (device configuration A) or ITO/ $\mathrm{MoO}_{3}(5 \mathrm{~nm}) /$ Fluo-2 $(40 \mathrm{~nm}) / \mathrm{BCP}(10 \mathrm{~nm}) / \mathrm{Alq}_{3}(20 \mathrm{~nm}) / \mathrm{LiF}(1 \mathrm{~nm}) / \mathrm{Al}(80 \mathrm{~nm})$ (device configuration B) (see Figure 2) [19-21]. The luminance-voltage $(L-V)$ curves obtained for the two device structures are presented in the Figure 3. Interestingly, major differences could be found. First, a turn-on voltage of $3.4 \mathrm{~V}$ was determined for devices fabricated with the configuration A whereas it decreases to only $2.8 \mathrm{~V}$ for the second configuration. Conversely, the highest luminance was found for the first configuration, the brightness peaking at $23,800 \mathrm{~cd} / \mathrm{m}^{2}$ at $10.4 \mathrm{~V}$ whereas a maximum luminance of only $3050 \mathrm{~cd} / \mathrm{m}^{2}$ was determined of type B-devices. Compared to previous results, a luminance about 17 times higher than that previously reported in the literature was determined for Fluo-2-based devices.

While examining the EL spectra (see Figure 4), a pure emission of Fluo-2 was obtained for type B-devices, whereas a contribution of TPBi could be detected for type A-devices with a shoulder at $377 \mathrm{~nm}$. Therefore, it can be concluded that Fluo-2 exhibits a hole-dominated transportation so that some holes 
can drift from the emissive layer into the adjacent electron-transport layer and recombine with electrons, resulting in the TPBi emission. This result also explains the low device characteristics reported in the literature for Fluo-2 (but also for Fluo-1 which is of similar structure), the hole-dominated transportation of Fluo-2 (but also of Fluo-1) favoring the electron-hole recombination at the cathode interface, leading to quenching and a significant reduction of the overall device efficiency [22]. Indeed, in these two studies, no hole blocking layer was used. As mentioned in the introduction section, naphthalimide-based emitters are often characterized by an electron-dominated transportation whereas in the present case, holes could drift inside the electron-transport layer i.e., TPBi (type A-devices). This counter-intuitive result can be assigned to the device structure that was selected as well as to the materials chosen to fabricate OLEDs. Indeed, smaller energy gaps could be found between layers enabling to inject and transport holes. In this context, the energy barriers being lower, holes can be injected and transported more easily than electrons, resulting in the electron-hole recombination close to the TPBi Layer. Ability of Fluo-2 to easily transport holes was confirmed by examining the variation of the CIE coordinates with the applied voltage. As shown in the Figure 4, a significant variation of the CIE coordinates could be detected for an applied voltage higher than $10 \mathrm{~V}$, evidencing a shift of the electron-hole recombination zone close to the TPBi layer at high voltage. This issue was addressed by introducing an additional BCP interlayer $(10 \mathrm{~nm})$ between the emissive layer and the electron-transport layer (device configuration C). An improvement of the EL performance with this second device configuration is also expected due to the suppression of the electron-hole recombination within the TPBi layer, what was confirmed experimentally (see Table 1).

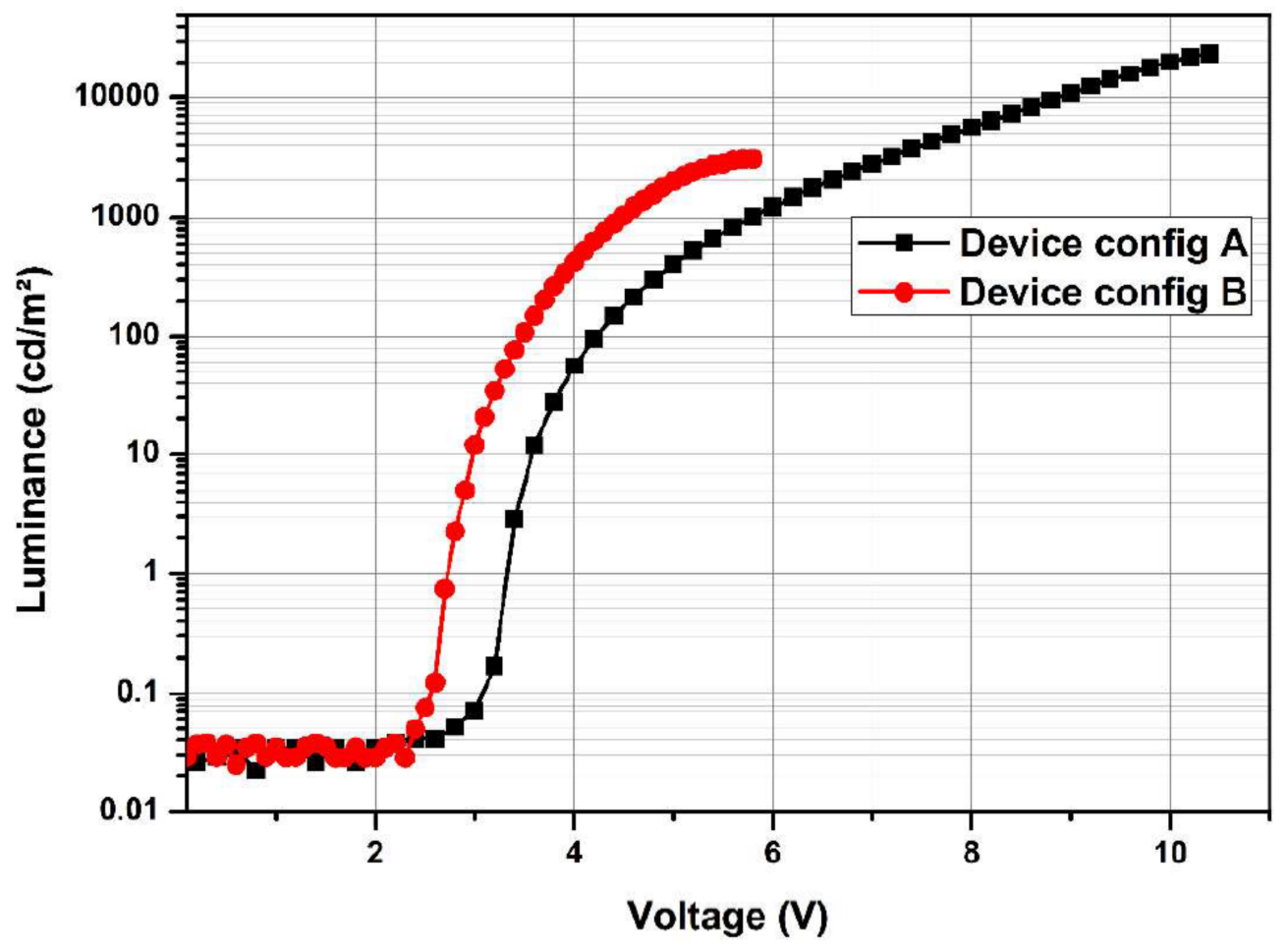

Figure 3. Luminance-voltage characteristics obtained with the two device configurations (A and B).

As shown in the Figure 5, addition of the BCP layer could efficiently confined electrons within the emissive layer since almost no variation of the dominant wavelength with the applied voltage was detected. A pure emission of Fluo-2 could be observed in the EL spectra recorded at various driving voltages, evidencing a confinement of holes within the emissive layer. As anticipated, enhanced electron-to-photon conversions were obtained for type C-devices. The luminance reached a maximum of $28,450 \mathrm{~cd} / \mathrm{m}^{2}$ at $11.0 \mathrm{~V}$. A maximum EQE of $3.11 \%$, a current and power efficiency of $10.00 \mathrm{~cd} / \mathrm{A}$ and $4.5 \mathrm{~lm} / \mathrm{W}$ were obtained, far from the values previously reported $(0.57 \mathrm{~cd} / \mathrm{A})$. 

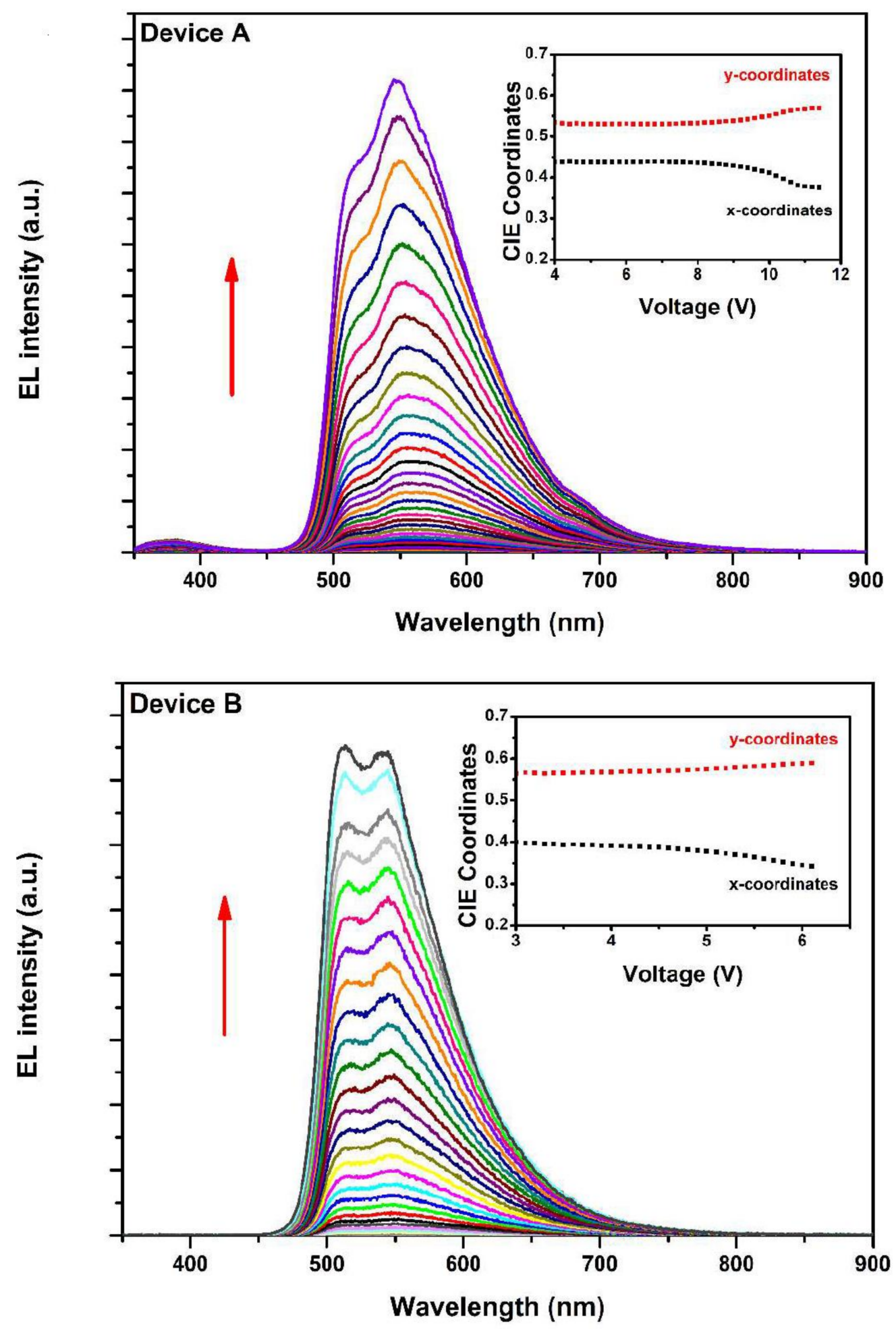

Figure 4. Electroluminescence spectra of OLEDs with device configurations A and B recorded by varying the applied voltage. Inset: variation of the CIE coordinates with the driving voltage.

Clearly, optimization of the device structure allowed to drastically improve the EL efficiency. OLEDs also showed a low current efficiency roll-off, with a decrease of less than $10 \%$ at $200 \mathrm{~mA} / \mathrm{cm}^{2}$. On the opposite, a more severe decrease of $35 \%$ at $200 \mathrm{~mA} / \mathrm{cm}^{2}$ was determined for the external quantum efficiency (See Figure 6). While coming back on the turn-on voltages of type B-devices and 
considering that type B- and type C-devices can both efficiently confine electrons and holes within the emissive layer, a lower turn-on voltage is observed for type B-devices $(2.8 \mathrm{~V})$ compared to type $\mathrm{C}$-devices $(3.4 \mathrm{~V})$ and this difference can be assigned to the difference of thickness. Indeed, the addition of the BCP interlayer has increased the overall thickness of $10 \mathrm{~nm}$, justifying the higher turn-on voltage for the corresponding devices.

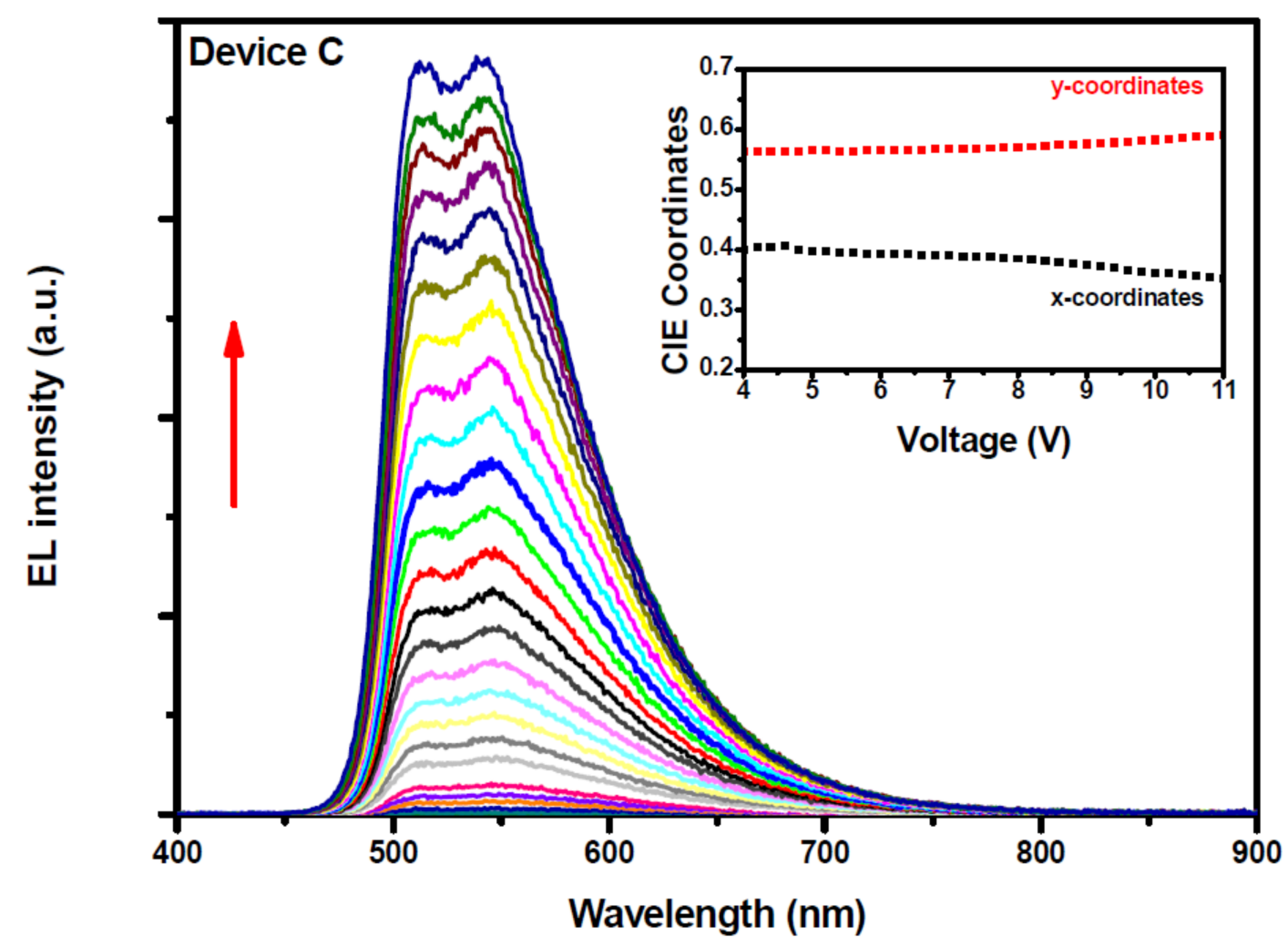

Figure 5. Electroluminescence spectra of OLEDs with device configuration $C$ recorded by varying the applied voltage. Inset: variation of the dominant wavelength with the driving voltage and CIE coordinates of the emitted light.

Finally, device lifetime of type C-devices was investigated. Indeed, for future applications in displays and lighting, operational stability of devices is a critical issue [23,24]. Devices were operated at room temperature and at constant applied voltage starting from an initial luminance of $1500 \mathrm{~cd} / \mathrm{m}^{2}$. As evidenced in the inset of Figure 7, an initial luminance corresponds to a driving voltage of $6.3 \mathrm{~V}$, and this value was maintained constant during the lifetime measurements. As observed in the Figure 7 , OLEDs could maintain over $90 \%$ of the initial luminance during $30 \mathrm{~min}$. This value is comparable to that reported for (mdppy) ${ }_{2}$ Iracac as triplet emitter in a comparable device structure [25]. A half-life of about 300 min was also determined. 


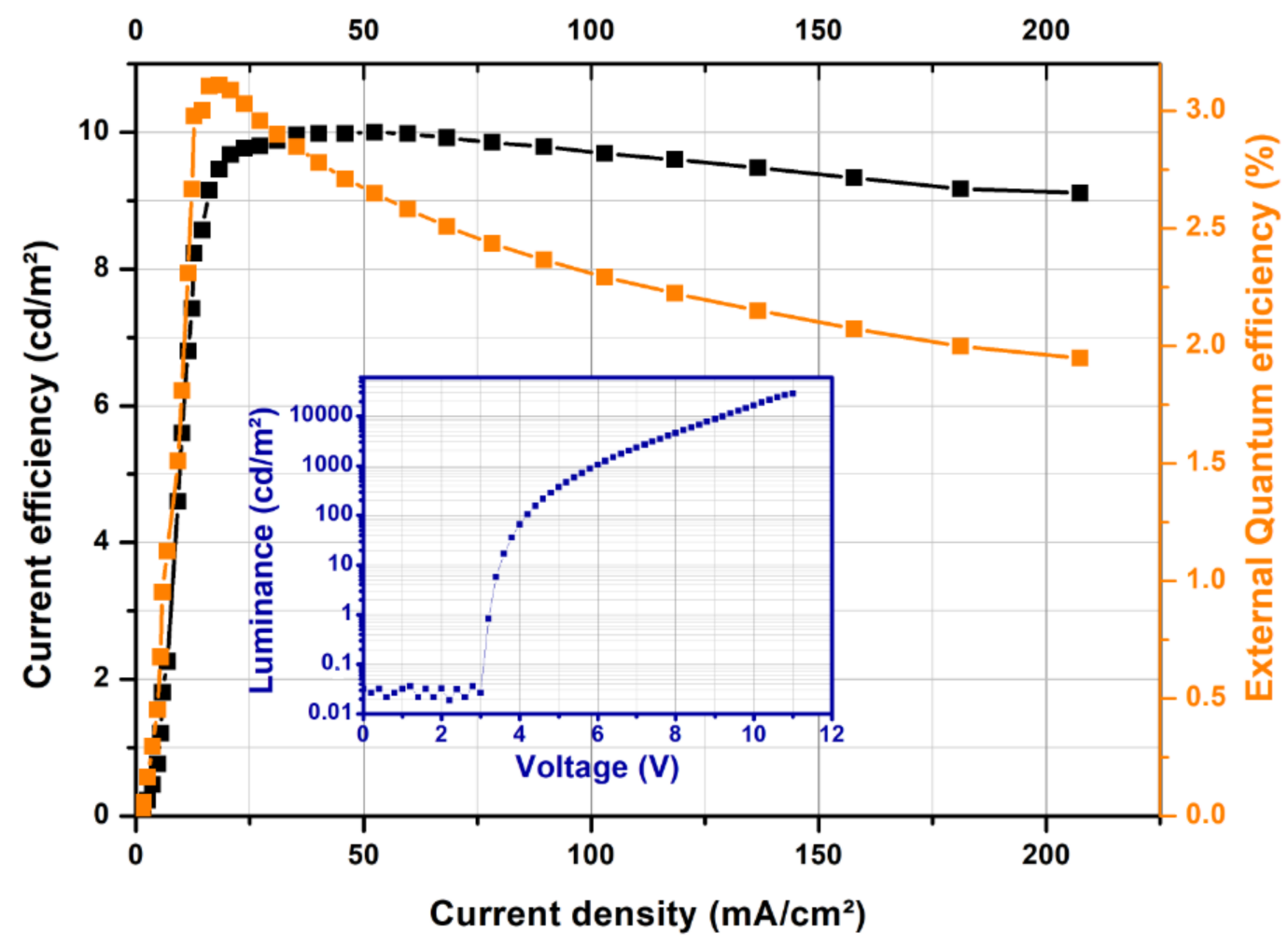

Figure 6. Current and external quantum efficiencies vs. current density characteristics for type C-OLEDs.

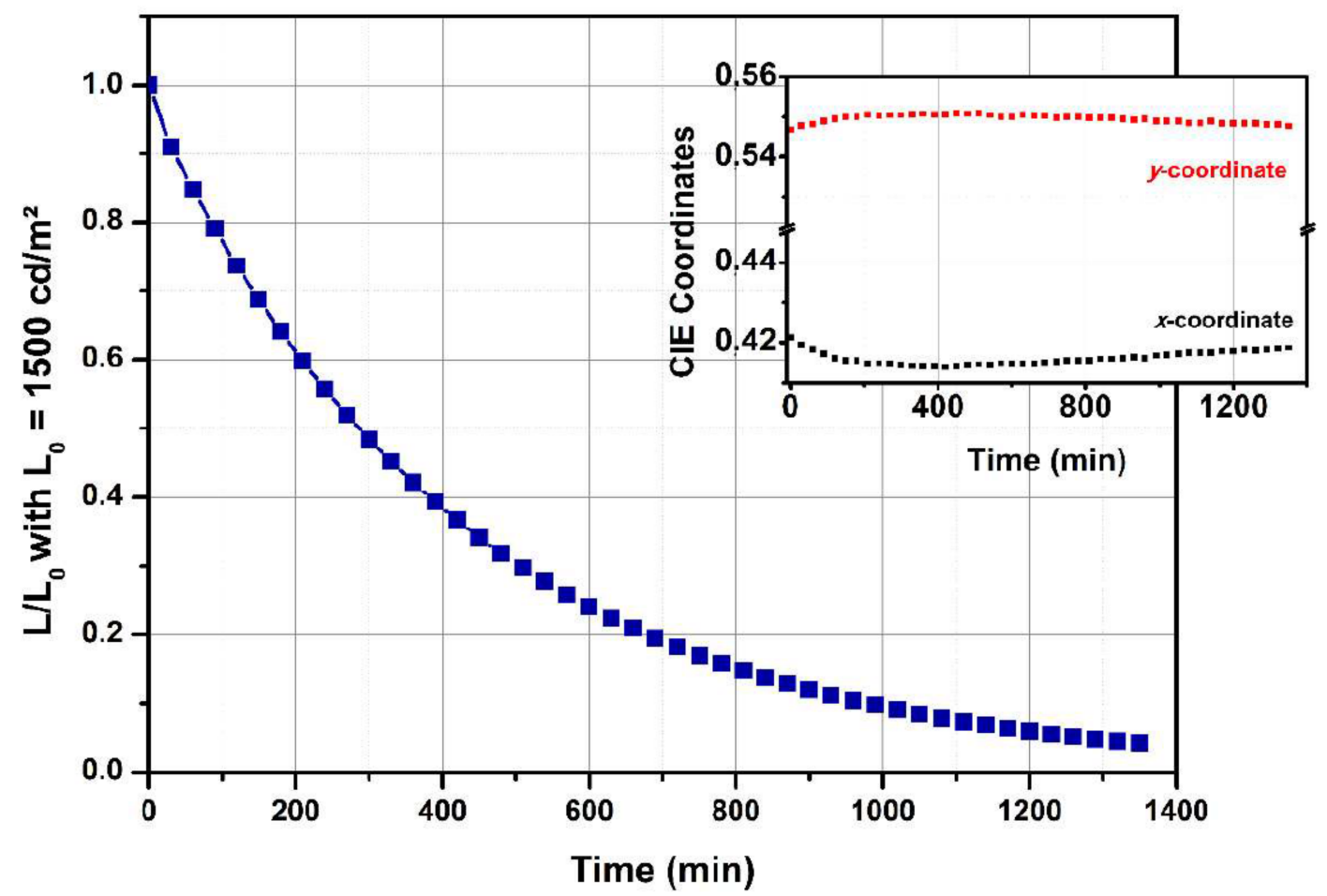

Figure 7. Time evolution of the normalized luminance, starting from an initial luminance of $1500 \mathrm{~cd} / \mathrm{m}^{2}$. Inset: Evolution of CIE coordinates over time.

These results indicate that the phthalimide accepting group is a promising structure for the design of light-emitting materials. While examining the modification of the emitted light over time, almost no 
color shift was observed after 1350 min of continuous operation. Only a decrease of the EL intensity of OLEDs was detected.

Table 1. Characteristics of OLEDs fabricated with Fluo-1 and Fluo-2.

\begin{tabular}{cccccccc}
\hline $\begin{array}{c}\text { Device } \\
\text { Configuration }\end{array}$ & $V_{\text {turn-on }}{ }^{[a]}$ & CIE $(\mathbf{x}, \mathbf{y})^{[b]}$ & $\begin{array}{c}\lambda_{\mathrm{EL}} \\
(\mathbf{n m})\end{array}$ & $\begin{array}{c}L \\
\left(\mathbf{c d} / \mathbf{m}^{2}\right)\end{array}$ & $\begin{array}{c}\text { Current eff. } \\
(\mathbf{c d} / \mathbf{A}) \text { [c] }\end{array}$ & $\begin{array}{c}\text { Power eff. } \\
(\mathbf{l m} / \mathbf{W})\end{array}$ & $\begin{array}{c}\text { EQE } \\
(\%)\end{array}$ \\
\hline $\mathrm{A}$ & 3.4 & $0.437,0.530$ & 571 & $\begin{array}{c}23,800 \\
(10.4 \mathrm{~V})\end{array}$ & 7.41 & 2.78 & 2.58 \\
B & 2.8 & $0.378,0.575$ & 562 & $\begin{array}{c}3050 \\
(5.8 \mathrm{~V})\end{array}$ & 2.80 & 1.80 & 0.76 \\
$\mathrm{C}$ & 3.4 & $0.396,0.564$ & 564 & $\begin{array}{c}28,450 \\
(11.0 \mathrm{~V})\end{array}$ & 10.00 & 4,50 & 3.11 \\
\hline
\end{tabular}

${ }^{[a]}$ Turn-on voltage at a brightness of $1 \mathrm{~cd} / \mathrm{m}^{2} .{ }^{[b]}$ Values measured at $5 \mathrm{~V} .{ }^{[c]}$ Maximum value.

\section{Conclusions}

A singlet emitter previously reported in the literature has been revisited in the context of multilayered devices. By optimizing the device tacking, a 20-fold enhancement of the current efficiency was determined. Parallel to this, a device lifetime comparable to that obtained with a standard triplet emitter was obtained, demonstrating the viability of the approach. Phthalimide-based emitters deserve to be more widely studied for the design of OLEDs, even in the context of the last generation of light-emitting materials, namely the Thermally Activated Delayed Fluorescence (TADF) emitters.

Acknowledgments: Authors thank the CNRS and Aix Marseille University for financial support.

Author Contributions: Frédéric Dumur and Didier Gigmes conceived and designed the experiments; Frédéric Dumur performed the experiments; Frédéric Dumur and Malika Ibrahim-Ouali analyzed the data; Frédéric Dumur, Malika Ibrahim-Ouali and Didier Gigmes wrote the paper.

Conflicts of Interest: The authors declare no conflict of interest.

\section{References}

1. Tang, C.W.; VanSlyke, S.A. Organic electroluminescent diodes. Appl. Phys. Lett. 1987, 51, 913-915. [CrossRef]

2. Shirota, Y. Photo- and electroactive amorphous molecular materials-Molecular design, syntheses, reactions, properties, and applications. J. Mater. Chem. 2005, 75, 75-93. [CrossRef]

3. D'Andrade, B.W.; Forrest, S.R. White Organic Light-Emitting Devices for Solid-State Lighting. Adv. Mater. 2004, 16, 1585-1595. [CrossRef]

4. Chen, C.T. Evolution of red organic light-emitting diodes: Materials and devices. Chem. Mater. 2004, 16, 4389-4400. [CrossRef]

5. Baranoff, E.; Curchod, B.F.E. FIrpic: Archetypal blue phosphorescent emitter for electroluminescence. Dalton Trans. 2015, 44, 8318-8329. [CrossRef] [PubMed]

6. Xu, H.; Chen, R.; Sun, Q.; Lai, W.; Su, Q.; Huang, W.; Liu, X. Recent progress in metal-organic complexes for optoelectronic applications. Chem. Soc. Rev. 2014, 43, 3259-3302. [CrossRef] [PubMed]

7. Yang, C.-H.; Tai, C.-C.; Sun, I.-W. Synthesis of a high-efficiency red phosphorescent emitter for organic light-emitting diodes. J. Mater. Chem. 2004, 14, 947-950. [CrossRef]

8. Zhao, B.; Zhang, T.; Chu, B.; Li, W.; Su, Z.; Wu, H.; Yan, X.; Jin, F.; Gao, Y.; Liu, C. Highly efficient red OLEDs using DCJTB as the dopant and delayed fluorescent exciplex as the host. Sci. Rep. 2015, 5, 10697. [CrossRef] [PubMed]

9. Hameed, S.; Predeep, P.; Baiju, M.R. Polymer light emitting diodes-A review on materials and techniques. Rec. Adv. Mater. Sci. 2010, 26, 30-42.

10. Braun, D.; Heeger, A.J. Visible light emission from semiconducting polymer diodes. Appl. Phys. Lett. 1991, 58, 1982-1984. [CrossRef]

11. Kamtekar, K.T.; Monkman, A.P.; Bryce, M.R. Recent advances in white organic light-emitting materials and devices (WOLEDs). Adv. Mater. 2010, 22, 572-582. [CrossRef] [PubMed] 
12. Yoon, J.-A.; Kim, Y.-H.; Kim, N.H.; Yoo, S.I.; Lee, S.Y.; Zhu, F.R.; Kim, W.Y. Highly efficient blue organic light-emitting diodes using quantum well-like multiple emissive layer structure. Nanoscale Res. Lett. 2014, 9, 191. [CrossRef] [PubMed]

13. Cacialli, F.; Friend, R.H.; Bouche, C.M.; Le Barny, P.; Facoetti, H.; Soyer, F.; Robin, P. Naphthalimide side-chain polymers for organic light-emitting diodes: Band-offset engineering and role of polymer thickness. J. Appl. Phys. 1998, 83, 2343-2356. [CrossRef]

14. Lee, S.-H.; Khim, D.; Xu, Y.; Kim, J.; Park, W.-T.; Kim, D.-Y.; Noh, Y.-Y. Simultaneous improvement of hole and electron injection in organic field-effect transistors by conjugated polymer-wrapped carbon nanotube interlayers. Sci. Rep. 2015, 5, 10407. [CrossRef] [PubMed]

15. Bloking, J.T.; Han, X.; Higgs, A.T.; Kastrop, J.P.; Pandey, L.; Norton, J.E.; Risko, C.; Chen, C.E.; Bredas, J.; McGehee, M.D.; et al. Solution-processed organic solar cells with power conversion efficiencies of $2.5 \%$ using benzothiadiazole/imide-based acceptors. Chem. Mater. 2011, 23, 5484-5490. [CrossRef]

16. Eftaiha, A.F.; Sun, J.-P.; Hill, I.G.; Welch, G.C. Recent advances of non-fullerene, small molecular acceptors for solution processed bulk heterojunction solar cells. J. Mater. Chem. A 2014, 2, 1201-1213. [CrossRef]

17. Dautel, O.J.; Wantz, G.; Almairac, R.; Flot, D.; Hirsch, L.; Lere-Porte, J.-P.; Parneix, J.-P.; Serein-Spirau, F.; Vignau, L.; Moreau, J.J.E. Nanostructuration of phenylenevinylenediimide-bridged silsesquioxane: From electroluminescent molecular J-aggregates to photoresponsive polymeric H-aggregates. J. Am. Chem. Soc. 2006, 128, 4892-4901. [CrossRef] [PubMed]

18. Mikroyannidis, J.A.; Tsai, L.-R.; Chen, Y. Synthesis, photophysics, electrochemical and electroluminescent properties of divinylene compounds with phthalimide moieties. Synth. Met. 2009, 159, 1195-1199. [CrossRef]

19. Dumur, F.; Bui, T.-T.; Péralta, S.; Lepeltier, M.; Wantz, G.; Sini, G.; Goubard, F.; Gigmes, D. Bis(diphenylamino) naphthalene host materials: Careful selection of the substitution pattern for the design of fully solutionprocessed triple-layered electroluminescent devices. RSC Adv. 2016, 6, 60565-60577. [CrossRef]

20. Dumur, F.; Beouch, L.; Peralta, S.; Wantz, G.; Goubard, F.; Gigmes, D. Solution-processed blue phosphorescent OLEDs with carbazole-based polymeric host materials. Org. Electron. 2015, 25, 21-30. [CrossRef]

21. Lessard, B.H.; Beouch, L.; Goubard, F.; Wantz, G.; Maric, M.; Gigmes, D.; Dumur, F. Poly(2-(N-carbazolyl) ethyl acrylate) as a host for high efficiency polymer light-emitting devices. Org. Electron. 2015, 17, 377-385. [CrossRef]

22. Campbell Scott, J.; Brock, P.J.; Salem, J.R.; Ramos, S.; Malliaras, G.G.; Carter, S.A.; Bozano, L. Charge transport processes in organic light-emitting devices. Synth. Met. 2000, 111-112, 289-293. [CrossRef]

23. Jeong, H.; Shin, H.; Lee, J.; Kim, B.; Park, Y.-I.; Yook, K.S.; An, B.-K.; Park, J. Recent progress in the use of fluorescent and phosphorescent organic compounds for organic light-emitting diode lighting. J. Photon. Energy 2015, 5, 057608. [CrossRef]

24. Hung, L.S.; Chen, C.H. Recent progress of molecular organic electroluminescent materials and devices. Mater. Sci. Engineer. R Rep. 2002, 39, 143-222. [CrossRef]

25. Guo, K.; Wang, H.; Wang, Z.; Si, C.; Peng, C.; Chen, G.; Zhang, J.; Wang, G.; Wei, B. Stable green phosphorescence organic light-emitting diodes with low efficiency roll-off using a novel bipolar thermally activated delayed fluorescence material as host. Chem. Sci. 2017, 8, 1259-1268. [CrossRef] [PubMed]

(C) 2018 by the authors. Licensee MDPI, Basel, Switzerland. This article is an open access article distributed under the terms and conditions of the Creative Commons Attribution (CC BY) license (http://creativecommons.org/licenses/by/4.0/). 